\title{
La Peculiar Reforma Laboral Mexicana de 2012
}

\section{The Peculiar Labor Law Reform of 2012}

AUTOR: Ángel Guillermo Ruiz Moreno

SUMARIO: I. Contextualización del tema abordado. II. Las razones de la reforma laboral del $1^{\circ}$ de diciembre de 2012. III. El derecho humano al trabajo y su exigibilidad en base a la "Declaración Universal de los Derechos Humanos». IV. Bibliografía.

Resumen: El empleo decente y el derecho de acceso al servicio público de la seguridad social que le acompaña, son derechos sociales contemplados tanto en el artículo 123 de la Constitución Política Mexicana, como derechos humanos plasmados en la $<<$ Declaración Universal de los Derechos Humanos $>>$ de Naciones Unidas, un documento jurídicamente vinculante para todos los países del orbe.

La nueva forma de producir bienes y servicios, debido a la híper tecnología, cambió el mundo del trabajo en esta era del conocimiento. Es por ello que en la segunda década del siglo XXI, debido a factores exógenos de la economía globalizada, debería el empleo tener un enfoque innovador, máxime que se ha convertido en un serio problema de calado mundial ante el imparable crecimiento exponencial de la informalidad laboral.

Palabras Clave: Reforma laboral, derechos humanos, empleo decente.
Abstract: Decent employment and the right to access the public service of social security that goes with it, are social rights stipulated in article 123 of our Constitution, and in the United Nation's Universal Declaration of Human Rights, which is a document legally binding in every country in the globe.

The new way of producing goods and services, due to hyper technology, has changed the world of labor in this era of knowledge. And it is the reason why in the second decade of the XXI century, due to exogenous factors of the globalized economy, employment should have an innovative approach, especially since it has become a serious problem worldwide against the unstoppable exponential growth of informal labor.

Key Words: Labor law reform, human rights, decent employment.

La academia sin política es utopía; la política sin academia es tiranía Jesús Reyes Heroles

\section{Contextualización del tema abordado}

Hablar acerca de la reforma laboral mexicana del $1^{\circ}$ de diciembre de 2012, día de la trasmisión sexenal de la Presidencia de la re- 
pública y por ende una fecha simbólica en un país tradicionalmente presidencialista como el nuestro, es hablar de un evento inédito en la historia nacional considerando su rica tradición en materia de los Derechos Sociales.

El experimento de alternancia en el poder de inicios del siglo XXI fue una docena trágica en materia de asuntos sociales de gran calado, pese a la promesa política del Presidente saliente quien aseguró sería "el Presidente del empleo" (sic), cuando lo que menos hubo en el país fue eso precisamente: empleo.

Sin embargo, de alguna manera, habrá que reconocer que en los últimos meses de la administración de Felipe Calderón se rompió al fin el habitual marasmo legislativo en temas socialmente complicados, debido a la creación de la llamada Iniciativa Preferente tras reformarse el artículo 71 de la Constitución Política de los Estados Unidos Mexicanos (CPEUM), ${ }^{1}$ obligándose así al Congreso de la Unión a estudiar con plazos perentorios la postergada discusión de una reforma legal laboral del trabajo ordinario que, analizadas las circunstancias de la misma, no fue una reforma laboral propiamente dicha al limitarse a la modificación del texto de 230 artículos, la adición de 71 preceptos y la derogación de 34 numerales, lo que sumó un gran total de 335 artículos que sufrieron reforma de los otrora 1,010 artículos que contenía la Ley Federal del Trabajo (LFT) de 1970, sin duda la legislación reglamentaria más trascendente del mítico artículo 123 de nuestra Carta Magna. $^{2}$

En efecto, a lo largo del sexenio anterior - junto al par de años de la presente gestión Presidencial en que ya ha operado dicha reforma legal-, lo único cierto es que lo que menos ha habido en México es empleo digno o empleo decente, como suele llamarle la Organización Internacional del Trabajo (OIT) al empleo de duración indefinida, con prestaciones completas y con servicio público de seguridad social incluido.

\footnotetext{
${ }^{1}$ La aludida reforma data del 9 de agosto de 2012, y puede ser consultado el texto actual del tercer párrafo de la fracción IV, de dicho artículo 71 de la Constitucional federal, en el siguiente sitio web: http://www.Diputados.gob.mx/LeyesBiblio/pdf/1.pdf

${ }^{2}$ Decreto de reforma de la Ley Federal del Trabajo, publicada en el Diario Oficial de la Federación el 30 de noviembre de 2012, y en vigor en todo el país al día siguiente de su publicación. Ver en el sitio web: http://www.dof.gob.mx/nota_detalle.php?codigo=5280815\&fecha=30/11/2012
} 
Ciertamente los datos duros a nivel mundial nos mueven a pensar en otras realidades y a la inevitable incidencia de factores exógenos propios de un mundo globalizado en todos los órdenes, factores que lamentablemente no fueron considerados al efectuarse dicha reforma legal laboral.

Es factible afirmar entonces que los grandes ejes de la coloquialmente denominada reforma laboral - si es que la hubo, que conste-, podían reducirse brevemente, aún a riesgo de caer en reduccionismos peligrosos, en los que enseguida se enuncian:

- Evitar la discriminación laboral;

- La creación de nuevos tipos de contratación laboral (v.gr.: contrato a prueba, por capacitación y por temporada);

- Una mayor flexibilización en las relaciones laborales;

- Mejorar el acceso al denominado "mercado laboral" (sic);

- Alcanzar una mayor productividad y calidad del trabajo;

- Regular la figura del outsourcing o subcontratación;

- Establecer las figuras jurídicas del hostigamiento sexual, el mobbing y acoso laboral;

- Crear dos nuevas causales de despido;

- Topar el monto de los salarios vencidos en los litigios laborales;

- Privilegiar la mediación y la conciliación en la solución de conflictos laborales; y,

- Establecer al fin un procedimiento sumario en materia de asuntos de seguridad social. ${ }^{3}$

Sin embrago, la mayoría de los aportes de dicha reforma a la LFT, ya en la práctica no se ven por ningún lado ni se han visto reflejados en una mejor relación entre los factores de la producción; tampoco han incidido en conseguir empleo ni productividad, ya no digamos contra con una mejor justicia laboral, pues no han podido permear todavía en la sociedad los objetivos buscados y para colmo no disfruta dicha reforma de una legitimación social suficiente que le vuelva aplicable en esta dura realidad laboral de la segunda década del siglo XXI.

\footnotetext{
${ }^{3}$ Para mayores datos sobre los motivos, ejes, alcances y opiniones oficialistas y académicas acerca de la reforma laboral, recomendamos la lectura del libro: Reforma laboral, derecho del trabajo y justicia social en México, publicado por la Unidad General de Asuntos Jurídicos de la Secretaria de Gobernación (SEGOB) del Gobierno Federal, México, 2013. El libro puede ser consultado en: http://ordenjuridico. gob.mx/Publicaciones/Libros2013/laboral-2013-web.pdf
} 
Aprobada por mayoría por el Congreso de la Unión, frente a la férrea oposición de los grupos políticos de izquierdas, pese a haberse modificado el $35 \%$ del texto de la LFT anterior, en la realidad cotidiana casi nada ha cambiado en el país; todo sigue igual que antes a pesar del discurso triunfalista de las autoridades laborales tanto federales como estaduales. Es por ello que sus defensores, quienes sistemáticamente han abordado esta supuesta "reforma laboral", confundiendo la ley con la ciencia jurídica, para intentar justificarla suelen reducir el tema-problema a simples postulados, a tecnicismos legales e ideas de una justicia social difusa, como sí este tema laboral no tuviera en la vida real un enorme peso e impacto social, político y humano.

Un solo dato a manera de botón de muestra. Pese a la enorme oportunidad de hacer un cambio trascedente en materia laboral en México, por presiones sectoriales y una inadecuada negociación política previa, quedó intocada en la pretendida "reforma laboral" (sic) el texto del actual artículo 123 de la CPEUM; de manera que el legislador secundario en la redacción de diversas disposiciones legales, al excederse del texto Constitucional, impuso condiciones, exigencias y/o modalidades que rebasan los topes mínimos y máximos previstos en el Apartado "A" del artículo 123 Constitucional; lo cual genera que algunas de dichas normas nacieran a la vida jurídica con una patente inconstitucionalidad, la que más temprano que tarde habrá de emerger al agotarse la vía jurisdiccional.

Así las cosas, afirmamos pues que si acaso hubo en México alguna reforma laboral lo fue a partir de la modificación del artículo $1^{\circ}$ de nuestra Carta Fundamental en materia de los derechos humanos, ${ }^{4}$ por la sencilla razón de que el Derecho del Trabajo -y su habitual complemento: el Derecho de la Seguridad Social-, se hallan contemplados como tales en los artículos del 22 al 25 de la «Declaración Universal de los Derechos Humanos» de Naciones Unidas (DUDH), ${ }^{5}$ como intentaremos argumentalmente demostrarlo en este ensayo.

\footnotetext{
${ }^{4}$ Reforma del artículo 10 de la Constitución Política de los Estados Unidos Mexicanos, publicada en el Diario Oficial de la Federación el 10 de junio de 2011, en vigor en todo el país al día siguiente de su publicación. Ver en: http://dof.gob.mx/nota_detalle.php?codigo=5194486\&fecha=10/06/2011

${ }^{5}$ «Declaración Universal de los Derechos Humanos», de la Organización de las Naciones Unidas, texto aprobado el 10 de diciembre de 1948, consultable en: http://www.un.org/es/documents/udhr/
} 
El presente es muy complicado, cierto; empero, visto objetivamente la situación del empleo en el país, el futuro luce todavía más ominoso e inquietante en materia laboral, sobre todo para los jóvenes y otros grupos vulnerables. Por eso es que importa tanto analizar el tema de dicha reforma legal a la luz de los derechos humanos.

\section{Las razones de la reforma laboral del $1^{\circ}$ de diciembre de 2012}

El fantasma del desempleo espanta ahora a lo largo y ancho de todo el planeta, y desde luego México no podría ser la excepción. Los factores negativos para nuestra economía, provocados por el débil crecimiento del país en los últimos años, aunado a la torpe idea de buscar a toda costa la flexibilización del "mercado de trabajo" (sic) nacional y teniendo en mente a la productividad laboral como gran aspiración teleológica, junto a otra serie de factores exógenos, nos obligan a ser proactivos para paliar al menos el enorme problema laboral del país.

La inevitable globalización de los mal llamados "mercados laborales, donde México es uno de los grandes "maquiladores" al ofrecer mano de obra barata y por ende resulta muy competitivo-, aunado a la crisis financiera mundial conocida como la Gran recesión de mediados del año 2008, han trasformado radicalmente el entorno laboral en el país. El empleo decente -que nuestra Carta Magna define con acierto como empleo digno y socialmente útil-, decae inercialmente como una constante en todo el planeta, debido al imparable crecimiento exponencial del trabajo informal, el cual, atendiendo las estadísticas del Instituto Nacional de Estadística y Geografía (INEGI) llegó ya en nuestro país al $60.1 \%$ de la población activa, la que a falta de empleo ha debido optar por la alternativa de la llamada auto ocupación de sobrevivencia del sector informal. ${ }^{6}$

Pero no sólo es México víctima de este problema. Hablamos de una tendencia de gran calado mundial, como lo confirman los Informes estadísticos que maneja la propia $\mathrm{OIT}^{7}$

${ }^{6}$ INEGI, Encuesta Nacional de Ocupación y Empleo, relativa al tercer trimestre de 2012, citada en el Boletín de Prensa $N^{\circ}$ 449/12 del 11 de diciembre de 2012, y consultable en la web:

http://www.inegi.org.mx/inegi/contenidos/espanol/prensa/Boletines/Boletin/Comunicados/Especiales/2012/diciembre/comunica3.doc

${ }^{7}$ Ver los datos correlacionados al decrecimiento del empleo decente, en la página web de la OIT: 
Un par de datos duros de la propia OIT — por lo tanto innegables e irrefutables-, nos ayudarán a contextualizar de mejor manera el injusto panorama global del sector informal del trabajo "en negro" y la "economía subterránea", obligándonos a meditar seriamente para efectuar primero un diagnóstico situacional objetivo, veraz y realista, y ya después buscar con creatividad e ingenio alternativas viables y factibles de contención del problema... máxime cuando el complejo asunto de la informalidad laboral se da incluso en el propio sector formal de la economía.

Dicho problema ha obligado a la OIT, desde inicios de este siglo $\mathrm{XXI}$, así no lo reconozca aun abiertamente, a redireccionar sus políticas acerca del empleo formal para apuntar directamente al problema del trabajo informal, analizándose con gran preocupación las razones de fondo que subyacen en el crecimiento exponencial de la auto ocupación laboral junto a las economía paralelas subterráneas que suelen ir a éstas aparejadas.

El punto de inflexión es que millones de mujeres y hombres de todas las edades, desde niños hasta ancianos, inermes frente a la dura realidad cotidiana, al no poder satisfacer sus necesidades personales y familiares son a diario tentados por el crimen organizado que suele esconderse detrás del sector informal; precisamente por eso es que importa tanto el tema de la informalidad laboral en México, pues por una parte a los informales los repliega la policía y, por la otra, los está esperando el crimen organizado para utilizarlos sin control alguno por parte del Estado. ${ }^{8}$

Un par de datos estadísticos que maneja la OIT resultarán altamente ilustrativos para dimensionar la gravedad del problema actual del empleo formal y los porqués de la informalidad laboral creciente, a saber:

a) A lo largo del siglo XXI, la constante invariable en todo el mundo es que de 8 de cada 10 nuevas ocupaciones (sic) que se crean -que no empleos, porque trabajo y empleo no son

\footnotetext{
http://www.ilo.org/global/statistics-and-databases/lang--es/index.htm

${ }^{8}$ Para una mayor información acerca del trabajo informal en México y su eventual protección, recomendamos la lectura del libro de nuestra autoría intitulado: Seguridad Social obligatoria para trabajadores migrantes e informales, coedición de la Universidad de Guadalajara y el Instituto Jalisciense de Investigaciones Jurídica. Editorial Porrúa, México, 2011.
} 
sinónimos-, se han creado precisamente en el sector informal de la economía; $y$,

b) En congruencia con el dato anterior, también 8 de cada 10 habitantes del planeta carecen de un servicio público efectivo de seguridad social. ${ }^{9}$

Por eso ante tan complicado entorno global, urgía efectuar en México un ajuste al marco Constitucional y legal a fin de adaptarse a la dura realidad de la preminencia del denominada trabajo autónomo a lo largo y ancho del planeta (un gran tema éste al que no nos referiremos aquí por razones de espacio). ${ }^{10}$ Nuestra frágil economía por un lado, y por el otro lado las presiones internacionales, nos obligaban como nación a asumir posturas y decisiones al respecto.

Era esta la gran oportunidad histórica de acabar con los mitos que tanto cultivamos los mexicanos, romper los atávicos paradigmas y cartabones obsoletos - como la lucha de clases, que de suyo poco se da en el ámbito laboral contrario a lo que se supone-, y estaba puesta la mesa para sentarse, discutir, convencer y actuar, sobre todo considerando la temática trascedente de los derechos humanos.

Sin embargo, los "pagos de facturas" del proceso post electoral del 2012 y la evidencia que desde un inicio ya estaba prácticamente "cocinada" la reforma a la LFT, hicieron que pasara la reforma tal cual venía la Iniciativa, con todas sus deficiencias, contradicciones y errores, sin haber escuchado jamás a los académicos que propugnábamos por corregir los errores estructurales de que adolecía dicha Iniciativa. Así, se cambió una buena parte del texto de la LFT y quedó pendiente su eventual instrumentación -lo que por cierto a estas alturas todavía no se consigue-. Fue una oportunidad perdida que millones de mexicanos lamentaremos por mucho tiempo.

Se nos olvidó que la nueva forma de producir bienes y/o servicios en esta híper tecnologizada era del conocimiento, vino a cambiar radicalmente el mundo del empleo a nivel global y por supuesto local.

\footnotetext{
${ }^{9}$ Ver el pdf de la OIT: Medición del trabajo informal, en: http://www.ilo.org/wcmsp5/groups/public/--ed_emp/---emp_policy/documents/publication/wcms_229450.pdf

${ }^{10} \mathrm{Al}$ lector se sugiere leer el artículo de Eduardo Román Vaca, intitulado: "La figura del trabajador autónomo económicamente dependiente, y su laboralización en el Estatuto del trabajador autónomo", publicado en el Boletín Adapt 1/2013, de Italia, y consultable en el siguiente sitio web:

http://www.adapt.it/boletinespanol/index.php?option=com_content\&view=article\&id=99
} 
El entorno exigía una renovación absoluta en materia laboral, la que debía partir de una reforma integral y profunda al otrora mítico artículo 123 de nuestra Carta Magna; pero la clase política se negó a modificarlo pese a ser una especie de "dique de contención" a cualquier propuesta renovadora en materia de empleo formal en tanto aquél siga vigente.

La idea de fondo -inteligente para algunos, maquiavélica para otros- era una sola: actualizar a toda costa los ya rebasados cuanto obsoletos marcos legales vigentes en México en materia de empleo, al ser el nuestro un país reacio al cambio y adepto a los mitos históricos, muy a pesar de su rica tradición en materia laboral y en temas sociales de gran calado.

Habrá que entenderlo entonces: fue en ese complejo entorno global y nacional como se efectuó - con toma de tribuna incluida por parte de los opositores-, la mal llamada "reforma laboral" en realidad no es tal, porque si bien se reformó una tercera parte de la LFT que regula el trabajo ordinario, no se ocupa de otro gran segmento de trabajadores como lo es el mayor empleador del país: el Gobierno federal, ni tampoco aborda el tema de los trabajadores subordinados al servicio de las 32 entidades federativas y los 2.441 municipios del país, cuya normativa laboral quedó de suyo intocada pues simplemente no hubo reforma alguna en materia del Derecho Burocrático nacional.

Sin embargo, para generar nuevas fuentes de empleo decente se requiere de reformas congruentes con el "mercado laboral" internacional, para atraer inversión extranjera habrá que darles a los inversores de la seguridad jurídica indispensable para que arriesguen aquí su dinero. Sí, hablamos que es necesario efectuar una gran reforma fiscal y hacendaria en este mundo económicamente globalizado; de hacer una reforma en el ámbito administrativo que facilite la "tramitología" para abrir nuevas empresas; de una reforma energética nacionalista que abarate costos a los empresarios; de una reforma en ciencia y tecnología que aliente el talento humano necesario en esta era del conocimiento, viéndola más como una inversión social y no como un gasto; conjuntamente con otra serie de reformas estructurales más. Después de todo, al Estado no le toca crear empleo, sino las condiciones necesarias para que lo haya.

Y para lograrlo, opinamos habrá que innovar -innovación es aquí la palabra clave-, cambiando nuestro "chip" mental a fin de generar 
un renovado pensamiento por parte de todos los actores del juslaboralismo nacional, capaz de impactar positivamente en la manera de comprender este complejo fenómeno social y humano del trabajo que, siendo francos, ha puesto ya al Derecho del Trabajo y por extensión al Derecho de la Seguridad Social contra la pared. En nuestra particular opinión, no hay otra alternativa posible.

Hoy día, con base al artículo 23 de la «Declaración Universal de los Derechos Humanos», importa más el derecho al trabajo que el Derecho del Trabajo. Y ya sabemos los juristas que ninguna ley -ni la LFT, ni ninguna otra-, por sí mismas pueden generar más y mejores empleos, pues la misión del Derecho es regular la realidad, porque el cambio legal no modifica la realidad pues ésta, guste o no, es más sabia (y sobre todo más veloz) que el Derecho.

\section{El derecho humano al trabajo y su exigibilidad en base a la «Declaración Universal de los Derechos Humanos»}

El acceso a un empleo digno y socialmente útil, no sólo se encuentra establecido en el primer párrafo del artículo 123 de nuestra CPEUM, sino también en los artículos 23 y 24 de la "Declaración Universal de los Derechos Humanos» (DUDH), siendo entonces derechos fundamentales cuya característica especial es ser irrenunciables, inalienables e inextinguibles en razón de su propia naturaleza intrínseca. Por lo tanto, este derecho puede también ser considerado, además de un derecho humano, como un derecho social exigible al Estado ${ }^{11}$ sin dejar de establecer aquí que en este mundo globalizado en todos los órdenes, el crucial tema de los derechos humanos se ha convertido en un asunto no sólo prioritario, sino lo políticamente correcto en casi todo el orbe.

Efectivamente, la fuerza jurídica vinculante de la DUDH, a pesar de sus más de sesenta años de existencia y contando, apenas comienza a ser debidamente comprendida por los juristas e investigadores del Derecho Social iberoamericano, sobre todo tras el complejo proceso

\footnotetext{
${ }^{11}$ RUIZ MORENO, Ángel Guillermo (coordinador). El Derecho Social a inicios del siglo XXI. Una visión en conjunto. Publicado por Editorial Porrúa en coedición con la Universidad de Guadalajara, México, 2006, pp. 1-20.
} 
de constitucionalización de los derechos sociales a que diera lugar dicho documento trascendente, algo observado en América Latina entera durante la segunda mitad del siglo XX y sin olvidar aquí los complicados procesos socio jurídicos que tuvieron lugar en la península ibérica.

Así, cuando hablamos del derecho de acceso a un empleo formal regulado, enfrentamos, como sucede en multiplicidad de temas de calado social de la más inversa índole, un sinnúmero de problemas en su análisis jurídico.

Para nosotros es indudable que existe un amplio e incuestionable reconocimiento del derecho de acceso al trabajo y, por extensión, al servicio público de la seguridad social que suele acompañar al empleo decente, convirtiéndose en una obligación inexcusable del Estado atento a lo contemplado por los artículo 22 y 24 en materia laboral, así como 22 y 25 en materia de seguridad social. Así, por su enorme pertinencia para la total comprensión de lo aquí afirmado, trascribimos enseguida íntegramente tales preceptos de la DUDH ${ }^{12}$ :

En materia laboral:

Artículo 23.

1. Toda persona tiene derecho al trabajo, a la libre elección de su trabajo, a condiciones equitativas y satisfactorias de trabajo y a la protección contra el desempleo.

2. Toda persona tiene derecho, sin discriminación alguna, a igual salario por trabajo igual.

3. Toda persona que trabaja, tiene derecho a una remuneración equitativa y satisfactoria, que le asegure, así como a su familia, una existencia conforme a la dignidad humana y que será completada, en caso necesario, por cualesquiera otros medios de protección social.

4. Toda persona tiene derecho a fundar sindicatos y a sindicarse para la defensa de sus intereses.

Artículo 24.

Toda persona tiene derecho al descanso, al disfrute de tiempo libre, a una limitación razonable de la duración del trabajo y a vacaciones periódicas pagadas.

En materia de seguridad social:

\footnotetext{
${ }^{12}$ Declaración Universal de Derechos Humanos, aprobada en París, por la Asamblea General de la ONU, mediante resolución 217 A (III), con fecha 10 de diciembre de 1948. Ver texto íntegro en el sitio web de Naciones Unidas: http://www.un.org/es/documents/udhr
} 


\section{Artículo 22.}

Toda persona como miembro de la sociedad, tiene derecho a la seguridad social y a obtener, mediante el esfuerzo nacional y la cooperación internacional, habida cuenta de la organización y los recursos de cada Estado, la satisfacción de los derechos económicos, sociales y culturales, indispensables a su dignidad y al libre desarrollo de su personalidad.

\section{Artículo 25.}

Todos tenemos derecho a un nivel de vida adecuado, que asegure a nosotros y a nuestra familia, la salud, el bienestar y en especial, la alimentación, el vestido, la vivienda, la asistencia médica y los servicios sociales necesarios. Tenemos, asimismo, derecho a seguro en caso de desempleo, enfermedad, invalidez, viudez, vejez u otros casos de pérdida de nuestros medios de subsistencia por circunstancias ajenas a nuestra voluntad.

Tanto la madre que va a tener un hijo, como su hijo, deben recibir cuidado y asistencia. Todos los niños tienen los mismos derechos, esté o no casada la madre.

Desde luego, en nuestra tesis partimos de la premisa, siguiendo al jurista Jesús Rodríguez y Rodríguez, que por derechos humanos entendemos:

El conjunto de facultades, prerrogativas, libertades y pretensiones de carácter civil, político, económico, social y cultural, incluso los recursos y mecanismos de garantía de todas ellas, que se reconocen al ser humano, considerado individual y colectivamente. $^{13}$

Somos de la opinión que uno de los problemas que con frecuencia afronta la temática de los derechos humanos, es que no existe una definición conceptual universalmente aceptada —como suele ocurrir con enorme frecuencia en el ámbito de las ciencias sociales, en donde la doctrina jurídica, en nuestro caso, suele llenar estas lagunas jurídicas-; sin omitir señalar ahora que si hubiera una única definición conceptual se correría el enorme riesgo de que el tipo no alcanzase a ser omnicomprensivo, lo cual permitiría su eventual inobservancia.

Como quiera que sea, en esencia los doctrinistas jurídicos suelen coincidir en lo general de lo que debería ser un derecho humano, como se observa de la definición que aporta Antonio Enrique Pérez Luño, quien afirma se trata de:

Un conjunto de facultades e instituciones que, en cada momento histórico, concretan las exigencias de la dignidad, de la libertad de la igualdad humanas, las cuales de-

\footnotetext{
${ }^{13}$ Dicha definición, elaborada por Jesús Rodríguez y Rodríguez, se plasmó en el Diccionario Jurídico Mexicano, 13a edición, Tomo II, letras " $D-H$ ", Instituto de Investigaciones Jurídicas de la UNAM y Editorial Porrúa, México, 1999, pp. 1063 y sigs.
} 
ben ser reconocidas positivamente por los ordenamientos jurídicos a nivel nacional e internacional. ${ }^{14}$

Tengamos en cuenta que los derechos humanos son garantías jurídicas universales y fundamentales, que protegen a los individuos y a los grupos frente a las acciones que menoscaban las libertades fundamentales y la dignidad humana. Tales derechos son inherentes a todos los seres humanos sin distinción alguna de nacionalidad, lugar de residencia, sexo, origen nacional o étnico, color, religión, lengua, o cualquier otra condición. Por tanto, a los Estados les corresponde respetar, promover y proteger efectivamente los derechos humanos.

Ahora bien, al hablar de derechos humanos, como sucede con todos los derechos - sean éstos humanos, individuales o sociales-, si alguien es su recipiendario o titular, necesariamente debe haber un sujeto obligado a respetarlo o a obsequiarlo y, en la hipótesis de que tal derecho sea inobservado o violado, por lógica estaría obligado a su reparación.

En ese hilo de ideas, el sujeto obligado lo será siempre el propio Estado, dondequiera que se encuentre el individuo titular del mismo, porque los derechos humanos son inherentes a su condición y naturaleza, portándolo el propio individuo donde quiera que él vaya; sin dejar de puntualizar ahora que, por extensión lógica, los derechos humanos amparan también a las personas jurídicas al estar integradas éstas por personas humanas.

Todo lo antes expresado, es fundamental para la construcción sistemática del llamado nuevo constitucionalismo social —en buena medida programático, condicionado siempre a la voluntad política en cuanto a inversión social se refiere-, tratándose pues de un renovado constitucionalismo nacional que florece por doquier en la región latinoamericana alrededor de la segunda mitad del siglo $X X$, y que se recoge luego puntualmente, como basamento estructurado, en los propios textos de las Constituciones políticas de los países del área de América Latina entera, si bien no de una manera uniforme en cuanto a sus alcances y su eventual exigibilidad jurisdiccional por parte del recipiendario del servicio.

Así las cosas, la cuestión jurídica más trascedente a dilucidar ahora sería: ¿cómo es que la DUDH contribuye a ése nuevo constituciona-

${ }^{14}$ PÉREZ LUÑO, Antonio Enrique. Derechos Humanos, Estado de Derecho y Constitución, México, p. 48. Ver en sitio web: http://www.redalyc.org/pdf/427/42712017.pdf 
lismo social, de alguna manera distinto del que surgiera en México en la segunda década del siglo XX con la Constitución Política de 1917? Dicha interrogante planteada no es desde luego un tema menor, sino de la mayor relevancia jurídica por asuntos como el principio pro homine, el control de convencionalidad y el control difuso, claves para los juristas a partir de la reforma al artículo $1^{\circ}$ de nuestra CPEUM.

Hablemos entonces sobre la policitada «Declaración Universal de los Derechos Humanos» o DUDH, si bien nuestro análisis argumentativo lo haremos, por pertinencia metodológica, en literales por separado:

A) Para comenzar, recordemos que en la redacción original del texto de la DUDH, participaron de inicio representantes de 53 Estados Miembros de la ONU, nombrándose una Comisión Redactora que trabajó arduamente en este proceso para ponerse de acuerdo en el texto de un asunto que sería fundamental para la humanidad; para ello se trabajó durante un par de años, en un momento crucial para el planeta entero pues, tras la Segunda Guerra Mundial, el mundo se hallaba divido ideológicamente en dos bloques: el oriental y el occidental. ${ }^{15}$

La redacción final de un documento de una fuerza moral y ética enormes, resultó muy complicada, si bien al final se impuso la lógica humanística y sobre todo la buena fe; así, tras ser aprobada la DUDH al seno de Naciones Unidas en una votación "a mano alzada", de inicio adquiere el carácter de una recomendación no vinculante, conforme a los usos y costumbres del Derecho Internacional Público, así la misma DUDH contenga un elenco de los derechos básicos y elementales de todo individuo; ${ }^{16}$ su cuidado texto, resume valores morales universales inherentes a la propia condición humana, tales como: el derecho a la vida, a la libertad, a la libre opinión, a no ser

\footnotetext{
${ }^{15}$ Fue una grandiosa tarea a cargo de la Comisión redactora, encabezada por Eleanor Roosvelt (EEUU), y en la que participaran personajes de la época de la talla de René Cassin (Francia), Charles Malik (Líbano), Peng Chun Chang (China), Hernán Santa Cruz (Chile), Alexandre Bogomolov / Alexei Pavlov (unión Soviétcia), Lord Dukeston / Geoffrey Wilson (Reino Unido), William Hodgson (Australia) y John Humprey (Canadá), dejando un legado histórico de enorme valía no sólo histórica sino jurídica al tratarse nada menos que el pilar de la actual normatividad internacional existente sobre los derechos humanos universales. Fuente consultada: "Los derechos humanos y las Naciones Unidas", documento que obra en el sitio web de la ONU en el sitio web: http//www.un.org/spanish/geninfo/faq/hr2.htm ${ }^{16}$ Datos extraídos de la publicación $60^{\circ}$ Aniversario de la Declaración Universal de los Derechos Humanos, 1948-2008, editada por la Oficina del Alto Comisionado para los Derechos Humanos de la ONU, México, 2007, p. 9. http://www.un.org/es/events/humanrightsday/udhr60/
} 
discriminado, a la salud, al acceso a la justicia, así como derechos a la dignidad, igualdad y equidad, junto a un elenco más de derechos fundamentales del individuo.

B) El amplio catálogo de derechos básicos - expresos o inferidosque constan en la DUDH, aparte de ser de todos los individuos, también son, en lógica consecuencia, derechos sociales porque vivimos todos en sociedades organizadas; por ende, en razón de su propia naturaleza intrínseca, los derechos humanos tienen la características de ser inalienables (no son negociables), irrenunciables (nadie puede renunciar a ellos bajo ninguna circunstancia), e inextinguibles (nunca se extingue el derecho de acceso a los mismos), adquiriéndose tales derechos humanos por el simple hecho de ser eso: personas humanas.

Nos queda muy claro que, si bien ningún derecho es absoluto debido a que todos sin distingo tienen límites, también lo es que tales límites deben ser siempre razonables, en una razonabilidad -que no discrecionalidad-que debe ser correcta y jurídicamente argumentada por el Estado, como sujeto obligado. Por ello es que tales derechos humanos fundamentales se convierten en fuente formal del Derecho, tanto nacional como internacional, debido a su enorme fuerza ética y moral, ya que por ejemplo, en materia laboral o de seguridad social, al establecerse parámetros claros en los artículos del 22 al 25 de la DUDH, tales principios proclamados deben utilizarse y respetarse tanto en las legislaciones nacionales como, en su caso, en las convenciones internacionales acordadas, ya que por la protección social que se deriva del documento referido y estando en juego nada menos que la dignidad de vida de todo individuo, resulta obligado a todos los más de siete mil millones de individuos que poblamos la tierra, el respeto y pleno acatamiento a tales disposiciones, brindando el Estado la mejor protección social posible a todos sus habitantes siempre en la medida de sus posibilidades y, de ser necesario, con la cooperación internacional.

Todas ellas entonces habrán de ser planificadas, instrumentadas y otorgadas por cada país a todos sus habitantes sin discrimen alguno, al través de los mecanismos jurídicos y las consecuentes políticas públicas creadas por el Estado específicamente para tal fin.

C) Por otra parte, algunos juristas sostienen todavía que la $D U D H$ es una simple Declaración - por más universal y fuente del Derecho que pueda ser-, y por lo tanto, que se trata entonces de una mera recomendación formulada en base a las reglas clásicas del Derecho 
Internacional Público; argumentan los críticos que su supuesta fuerza vinculante nacional e internacional no es lo suficientemente clara debido a que "afecta soberanías nacionales" (sic), y en consecuencia puede no existir a pesar de lo planteado en párrafos precedentes.

Pues bien, en vez de enfrascarnos ahora en estériles discusiones acerca de si la DUDH es o no un documento vinculante con pleno valor jurídico, al contener obligaciones de todos los Estados del orbe frente a sus ciudadanos y habitantes en general - junto con la discusión casi permanente de si estos son o no derechos sociales exigibles al Estado- ${ }^{17}$ lo que resulta innegable es que dicha Declaración Universal constituye el basamento de todas las normativas internacionales de derechos humanos existentes; siendo entonces un referente básico y clave, por su fuerza moral, en que se respaldan y sustentan los Convenios, los Tratados y los Pactos de diversa índole signados (algunos de ellos mundiales, continentales o regionales), en materia de derechos humanos. Nadie debería dudar hoy día que gusten o no, todos ellos son verdaderos instrumentos jurídicos vinculantes, si se analizan a la luz del propio Derecho Internacional e interno de cada país.

A todos debería quedarnos perfectamente claro ya, bajo tal argumentación, la fuerza vinculante de la DUDH. Empero, no se trata sólo de un aspecto jurídico-filosófico, sino de un asunto que por desgracia casi nunca ha sido debidamente razonado en Tribunales latinoamericanos.

Intentando nosotros colmar ahora ese sentido vacío, ponemos a la par el tema en el tapete de las discusiones serias, responsables y comprometidas, la compleja temática abordada que suele ser olvidada por legisladores, gobiernos y jueces en América Latina entera, pues no ignoramos que hay países -e incluso bloques de países, como los islámicos por razones más religiosas que políticas, así como algunos asiáticos y hasta latinoamericanos-, quienes con insistencia piden a la ONU que sea "reexaminada" la DUDH en el contexto histórico y

\footnotetext{
${ }^{17} \mathrm{El}$ polémico y fascinante tema de los derechos sociales exigibles al Estado, por razones de pertinencia metodológica es imposible abordarlos en esta obra; empero, pueden ser consultados sus alcances en nuestro ensayo: "Derechos sociales exigibles", que aparece publicado en la obra colectiva Agenda para el Desarrollo de México (constante de 15 volúmenes), Serie "Conocer para Decidir», del Consejo Nacional de Universitarios. LX Legislatura del Congreso de la Unión, co-editada por la UNAM y Editorial Miguel Ángel Porrúa, coordinada por José Luis Calva, Volumen 12 “Derechos sociales y desarrollo incluyente", México, 2007, pp. 74 a 91.
} 
cultural de cada país en lo particular, argumentando como punto de debate el que sus sociedades están estructuradas tradicionalmente a partir de los deberes del ciudadano, más no de los derechos; aduciéndose para ello las notorias diferencias entre las diversas culturas $\mathrm{y}$ tradiciones existentes en el planeta. ${ }^{18}$

D) Pues bien, intentando fijar ya nuestra personal postura al respecto, nos hallamos convencidos de la fuerza jurídica y moral vinculante de la DUDH. Porque como ya dijimos antes, es verdad que en la aprobación final de dicha Declaración Universal participaron representantes de 53 Estados Miembros de la ONU, mismo número que hoy día, por tradición histórica, cuenta la Comisión de Derechos Humanos de Naciones Unidas, los que se reúnen anualmente en Ginebra, Suiza, para diseñar las políticas mundiales en esta delicada materia. ${ }^{19}$

Es incuestionable que la DUDH -en esencia y de origen una mera recomendación no necesariamente vinculante, así contenga un elenco de derechos elementales de todo individuo-, fue una grandiosa idea y una enorme tarea unificadora que corrió al cargo de la Comisión nombrada para tales efectos. ${ }^{20}$ Sin embargo, aparte de valores éticos y morales, no hay duda acerca de que su contenido es también esencialmente jurídico, al utilizarse precisamente la palabra derechos, con toda la fuerza que ello supone. Derechos es pues aquí, en esta argumentación, la palabra clave, porque no se habla de simples expectativas que quedan al libre albedrío discrecional de los representantes en turno del Estado; se fijan en la DUDH derechos humanos y sociales cuya naturaleza intrínseca es evidente al ser exigibles al Estado como el obligado a otorgarlos y, en su caso, obligado también a reparar su ausencia o inobservancia.

Sin embargo, qué razón tenía Norberto Bobbio cuando afirmaba al respecto que: "...el problema de fondo relativo a los derechos humanos no es hoy tanto el justificarlos como el protegerlos."21 Protegerlos, claro está, de la irracionalidad de quienes en ejercicio del poder so-

\footnotetext{
${ }^{18}$ Véase: "La oposición a la Declaración Universal", de la ONG "Amnistía Internacional», en el sitio web: http://www.amnistiacatalunya.org/edu/es/historia/dh-oposicion.html

${ }^{19}$ Véase: Los derechos humanos y las Naciones Unidas", documento consultable en el sitio web de la ONU en: http//www.un.org/spanish/geninfo/faq/hr2.htm

${ }^{20}$ Datos extraídos de la publicación $60^{\circ}$ Aniversario de la Declaración Universal de los Derechos Humanos, 1948-2008, editada por la Oficina del Alto Comisionado para los Derechos Humanos de la ONU, México, 2007, p. 9. Ibídem.

${ }^{21}$ BOBBIO, Norberto. El tiempo de los derechos. Editorial Taurus, Grupo Santillana, Madrid, 1991.
} 
berano que les concede el sistema jurídico vigente de sus respectivos países, en su correspondiente tramo de responsabilidades abusan de su privilegiada posición en la toma de decisiones discrecionales y, por ende, al hacerlo, se sienten amenazados ante la indudable legitimación ética, moral y jurídica de un mandato de la envergadura de la referida DUDH, la que opinamos se ha convertido ya en fuente inagotable del Derecho Internacional en todo el planeta.

E) Argumentemos jurídicamente las razones de nuestra anterior afirmación, a la luz del Derecho Público Internacional. El reconocido tratadista uruguayo Héctor Gros Espiell, en un ensayo elaborado para conmemorar el Cincuentenario de la DUDH (y también de la "Declaración Americana de los Derechos y Deberes del Hombre"), ${ }^{22}$ entre otras cosas interesantes sobre las cuales deberíamos reflexionar todos, señaló:

La Declaración Universal ya está hoy citada e intocada en la jurisprudencia de la Corte Internacional de Justicia..., Tribunal que la ha entendido y valorado como inviolable e inobservable por ningún país o individuo del planeta, dando entonces por un hecho ya incontrovertible, más allá de lo que cada uno quiera pensar a este respecto, el que la Declaración Universal es una fuente de Derecho Internacional. ${ }^{23}$

Interesa sobremanera hacer énfasis en la juridicidad de dicha Declaración Universal porque el propio Héctor Gros nos brinda un dato de vital importancia jurídica a considerar, en el sentido de que si bien tal documento no es una resolución propiamente dicha sino una mera recomendación, lo hay duda de que la misma fija una pauta moral y política incuestionable que bien puede servir de ejemplo para contemplarse luego en las propias Constituciones Políticas nacionales, a fin de abrir un camino de evolución progresista con miras al futuro de

\footnotetext{
${ }^{22}$ La "Declaración Americana de los Derechos y Deberes del Hombre», la que es trascedente dado que creó la Organización de Estados Americanos (OEA) y es el primer antecedente de derechos humanos; fue aprobada en Bogotá, Colombia, también en 1948, pero un semestre antes que la DUDH. En sus artículos XVI y XXXV, también previene prestaciones relativas a la seguridad social. Consultable en el sitio web: http://www.oas.org/es/cidh/mandato/Basicos/declaracion.asp

${ }^{23}$ GROS ESPIELL, Héctor (Coordinador). Derechos Humanos. A 50 años de la Declaración Americana de los Derechos y Deberes del Hombre, y de la Declaración Universal de los Derechos Humanos. Universidad Católica de Uruguay en coedición con Editorial y Librería Jurídica Amalio M. Fernández, Montevideo, 1999, p. 42.
} 
un país avanzado en materia de asuntos humanos y sociales de gran calado.

En efecto, el razonamiento lógico-jurídico de Gros Espiell es impecable e implacable. Por su importancia, opinamos que merece ser transcrito para que el lector efectúe su propio análisis en esta controvertida cuanto poco explorada temática de la fuerza jurídica de la multicitada Declaración Universal:

La Declaración Universal se adoptó mediante una decisión en forma de resolución. Y resoluciones de la Asamblea General (de la ONU) son recomendaciones. Fue tomada por la Asamblea General en París el 10 de diciembre del '48. No hay que caer en el error tan común, incluso de alto nivel técnico, de decir: 'el país tal es signatario de la Declaración Universal'. Esto es un disparate jurídico. No hay ningún país signatario de la Declaración Universal, que se adoptó por votación. Y no con unanimidad, ya que tuvo seis abstenciones. Es tan común este error, que hace pocos días, en una reunión del Comité Consultivo de la UNESCO en esta materia, tuve que señalar que en el 'Manual para la Enseñanza de los Derechos Humanos' preparado por la Organización (División de Educación) se hacía referencia a los países signatarios de la Declaración Universal. Grave error. La Declaración Universal fue adoptada mediante voto de la Asamblea, que no fue abierta a la firma.

»Ahora bien, la consecuencia de que se adoptara mediante una resolución de la Asamblea General, en aquél momento, fue, como se dijo entonces: 'una mera recomendación...' Esto es lo que se pensaba en el '48. Y esto está muy claro en el Preámbulo de la Declaración Universal, cuando se expresara que es un ideal común por el que todos los pueblos deben esforzarse. ¿Por qué no se adoptó por unanimidad la Declaración Universal? No se adoptó por unanimidad porque se había rechazado, en el proceso de elaboración de la Declaración, la propuesta de incluir el derecho a la libre determinación de los pueblos.

»Por esta razón, la Unión Soviética y todos los países comunistas de Europa Oriental y Central se abstuvieron. Además Arabia Saudita por razones distintas participó con su voto negativo. Pero es curiosísimo y es uno de los más interesantes ejemplos que se pueden dar en Derecho Internacional, de cómo en un plazo relativamente breve, la Declaración Universal pasó de ser un mero ideal común, una pauta política y moral, a ser una fuente de obligaciones jurídicas exigibles. ${ }^{24}$

F) Resulta aconsejable que, si bien acorde a su naturaleza jurídica la DUDH en principio era tan sólo una recomendación, al amparo del principio pro personae o pro homine en su interpretación más favorable a la persona humana de nuestro actual artículo $1^{\circ}$ de la CPEUM, para fines técnicos y hasta pragmáticos se ha convertido aquella en un instrumento jurídico vinculante para todos los países —que resulta

\footnotetext{
${ }^{24}$ La cita transcrita, forma parte del ensayo jurídico de la autoría del propio Héctor Gros Espiell, intitulado: "Naturaleza jurídica y carácter de fuentes de Derecho Internacional de la "Declaración Americana de Derechos y Deberes del Hombre», y de la "Declaración Universal de los Derechos Humanos». Op cit., pp. 40-41.
} 
imposible de ignorar con independencia de si son o no Miembros de la ONU - al contener un catálogo de derechos humanos y sociales, que son de todos y para todos.

Porque siguiendo al contexto histórico que Héctor Gros Espiell y otros tratadistas han hecho sobre la evolución de la DUDH, analizándose la fuerza que cobró con el decurso de los años tenemos como hechos incuestionables que en 1968 -esto es, 20 años después de su proclamación-, en la «Conferencia de Teherán sobre Derechos Humanos», para festejar precisamente el vigésimo aniversario de la DUDH y contándose ya con la presencia de 120 Estados Miembros de la ONU (esto es, doblándose el número de los Miembros que originalmente la votaran en 1948), se declaró, ahora por unanimidad y desde luego sin ningún voto en contra o abstención, el que la policitada Declaración Universal constituía ya un instrumento internacional obligatorio para todos los Estados Miembros de la Comunidad Internacional. ${ }^{25}$

De tal suerte que la ONU entera, se manifestó unánimemente en 1968 no tanto para rendirle pleitesía como podría suponerse, sino más bien para reconocerle una jerarquía mayor y de suyo vinculante, en base al espíritu que le anima a la DUDH, valorando y validando de fondo lo que constituye su razón de ser y hacer, incluso por sobre la forma misma de simple recomendación de que disfrutaba desde un inicio. Se optaba así, para decirlo fácil y que mejor se entienda, "por empeñar la palabra, sin necesidad de firmas de por medio", o para expresarlo de manera más gráfica: bastó con alzar la mano en una votación económica unánime, para dar por hecho un acuerdo vinculante entre los representantes legítimos de 120 países del orbe; acuerdo que a distancia, viéndolo bien, más allá de que estuviese o no firmado, siempre podía respetarse o vulnerarse; por ello es que se optó mejor por reconocerle fuerza jurídica al compromiso pre adquirido, volviéndole perdurable al través del tiempo.

No hay duda entonces. Se pensaba más en la fuerza de la justicia y la paz social que podría alcanzarse en el mundo por la DUDH, que por el simple aspecto jurídico formal per se, pues, al final, ya fuese con 53 o con 120 votos a favor, la cuestión era la misma: seguía -y seguirá siendo- el tema de los derechos humanos, un asunto más

${ }^{25}$ GROSS ESPIELL, Héctor. Idem, p. 42. 
de índole moral y ético, que propiamente jurídico. Y lo moral, lo ético, no requiere de firma alguna que le dé pleno valor, si bien el comentario nos sirve para argumentar la fuerza jurídica vinculante, pues el planeta había evolucionado y aprendido de sus errores tras dos fatídicas conflagraciones mundiales acaecidas en la primera mitad del siglo XX, hasta el punto que el derecho a la libre determinación de los pueblos había sido ya incluido en el artículo $1^{\circ}$ de los dos Pactos de Derechos Humanos adoptados y abiertos a la firma por la Asamblea General de la ONU en $1966 .{ }^{26}$

G) Para finalizar ya nuestra argumentación vertida, acaso lo más importante de todo es poder constatar cómo en tan solo veinte años cambió radicalmente el enfoque acerca de la DUDH. Lo comprueba también, como aduce el propio Héctor Gros, otro hecho singular, éste sí con fuerza jurídica: en la $" 2^{\mathrm{a}}$ Conferencia Mundial de Derechos Humanos", celebrada en Viena en 1993, vuelve la comunidad internacional de la ONU —esta vez integrada nada menos que por 185 Estados Miembros-, a declarar nuevamente por unanimidad y por aclamación que dicha Declaración Universal es fuente de obligaciones jurídicas 'estrictu sensu'... Es decir, que ya es reconocida mundialmente como una fuente de Derecho Internacional en estricto sentido. ${ }^{27}$

Que nadie lo dude entonces: la Doctrina Jurídica -la que constituye una parte fundamental de la ciencia del Derecho, como los abogados sabemos-, ha concluido que la DUDH es en realidad una fuente de obligaciones jurídicas y por lo tanto vinculante para todos los países del planeta, formen parte o no de Naciones Unidas. Para ello, se han utilizado dos vías distintas, a saber:

a) La primera vía al considerar a la DUDH como fuente del Derecho por medio de la figura jurídica de la costumbre internacional en esta temática específica de los derechos humanos; y,

b) La segunda vía, al reconocer exprofeso a la Declaración Univer-

\footnotetext{
${ }^{26}$ Los también llamados "Pactos de Nueva York», son dos Tratados Internacionales sobre derechos humanos que fueron adoptados en el seno de la Asamblea General de las Naciones Unidas en la Resolución 2200A (XXI), del 16 de diciembre de 1966. Ellos son: a) el «Pacto Internacional de Derechos Civiles y Políticos»; y, b) el "Pacto Internacional de Derechos Económicos, Sociales y Culturales». Para mayor información ver el sitio web: http://www2.ohchr.org/spanish/law/ccpr.htm

${ }^{27}$ GROSS ESPIELL, Héctor. Ibídem, p. 42.
} 
sal como una más de las diversas fuentes formales del Derecho Internacional, previstas ya en el propio Estatuto de la Corte Internacional de Justicia de las ONU. ${ }^{28}$

En resumen, por su esencia y presencia, pero ante todo por su gran fuerza moral, por su importancia y trascendencia vital para todos los habitantes de este planeta, la «Declaración Universal de los Derechos Humanos» o DUDH se ha convertido hoy día en el documento más consultado y más traducido de la historia de la humanidad -incluso más que la propia Biblia-. Su contenido, guste o no la idea, es ya un derecho planetario socialmente legitimado.

De todo lo antes apuntado, se da ya por descontado que en todas las Constituciones Políticas nacionales - si bien en diversas formas e intensidades-, se encuentran plasmados ese elenco de derechos humanos establecido en la «Declaración Universal de los Derechos Humanos», ese breve pero magnífico documento histórico que ha hecho cambiar al mundo de ideas. México deberá hacerlo pronto, para bien de todos y sobre todo de los millones de jóvenes carentes de empleo digno.

Por lo tanto, la única defensa posible contra la policitada "reforma laboral”, será judicializar el tema. En última instancia, tocará a la Suprema Corte de Justicia de la Nación resolver si en verdad le asiste la razón a la clase trabajadora cuando individualmente o grupalmente se duelan de las inconstitucionalidades de que adolece la vigente LFT, haciendo valer sus derechos humanos al empleo digno, reclame acceso al servicio público de la seguridad social, pues el empleo sistemáticamente se ha precarizado en el país... aunque siendo sinceros, el futuro de dichos medios de impugnación sea por demás incierto, por lo que auguramos que serán los tribunales internacionales quienes terminen diciendo al respecto la última palabra.

El motivo de nuestra mayor inquietud como juristas es muy simple: cuando el Estado no tiene la razón, suele aplicar "las razones de Estado" para salirse con la suya. Y por lo tanto, en este espinoso tema abordado, las mejores conclusiones las tendrá el propio lector.

\footnotetext{
${ }^{28}$ Ver el artículo 38 del «Estatuto de la Corte Internacional de Justicia» de la ONU, con sede en La Haya, Países Bajos, en el sitio web: http://www.icj-cij.org/homepage/sp/icjstatute.php
} 
Libros:

BOBBIO, Norberto. El tiempo de los derechos. Editorial Taurus, Grupo Santillana, Madrid, 1991.

CALVA, José Luis (coordinador). "Agenda para el Desarrollo de México» (15 volúmenes), Serie Conocer para Decidir del Consejo Nacional de Universitarios. LX Legislatura del Congreso de la Unión, coeditada por la UNAM y Editorial Miguel Ángel Porrúa, Volumen 12 "Derechos sociales y desarrollo incluyente", México, 2007. ISBN: 978607-711-052-1.

"Diccionario Jurídico Mexicano», 13ª edición, Tomo II, letras "D-H". Instituto de Investigaciones Jurídicas de la UNAM y Editorial Porrúa, México, 1999. ISBN: 968-452-269-1.

GROS ESPIELL, Héctor (Coordinador). Derechos Humanos. A 50 años de la Declaración Americana de los Derechos y Deberes del Hombre, y de la Declaración Universal de los Derechos Humanos. Universidad Católica de Uruguay en coedición con Editorial y Librería Jurídica Amalio M. Fernández, Montevideo, 1999.

RUIZ MORENO, Ángel Guillermo (coordinador). EI Derecho Social a inicios del siglo XXI. Una visión en conjunto. Publicado en coedición con la Universidad de Guadalajara por Editorial Porrúa, México, 2006. ISBN: 970-07-7070-2.

RUIZ MORENO, Ángel Guillermo. Seguridad Social obligatoria para trabajadores migrantes e informales. Coedición de la Universidad de Guadalajara y el Instituto Jalisciense de Investigaciones Jurídicas. Editorial Porrúa, México, 2011. ISBN: 978-607-09-0735-7.

Secretaría de Gobernación. Unidad General de 
Asuntos Jurídicos. Reforma laboral, derecho del trabajo y justicia social en México. Dirección General Adjunta de Compilación y Consulta del Orden Jurídico Nacional, México, 2013. ISBN: 978607-427-217-8.

\section{Internet:}

http://www.Diputados.gob.mx/LeyesBiblio/pdf/1. pdf

http://www.dof.gob.mx/nota_detalle.php?codigo= $5280815 \&$ fecha $=30 / 11 / 201 \overline{2}$

http://ordenjuridico.gob.mx/Publicaciones/Libros2013/laboral-2013-web.pdf

http://www.un.org/es/documents/udhr/

http://dof.gob.mx/nota_detalle.php?codigo=5194 486\&fecha $=10 / 06 / 201 \overline{1}$

http://www.inegi.org.mx/inegi/contenidos/espanol/prensa/Boletines/Boletin/Comunicados/Especiales/2012/diciembre/comunica3.doc

http://www.ilo.org/global/statistics-and-databases/lang--es/index.htm

http://www.ilo.org/wcmsp5/groups/public/--ed_emp/---emp_policy/documents/publication/ wcms_229450.pdf

http://www.adapt.it/boletinespanol/index. php?option=com_content\&view=article\&id=99

http://www.redalyc.org/pdf/427/42712017.pdf

http//www.un.org/spanish/geninfo/faq/hr2.htm 
http://www.amnistiacatalunya.org/edu/es/historia/ dh-oposicion.html

https://www.oas.org/dil/esp/Declaraci\%C3\%B3n Americana_de_los_Derechos_y_Deberes_del_ Hombre_1948. pdf

http://www2.ohchr.org/spanish/law/ccpr.htm

http://www.oas.org/es/cidh/mandato/Basicos/declaracion.asp

http://www.icj-cij.org/homepage/sp/icjstatute.php 